\title{
Prolonged nerve blockade in a patient treated with lithium
}

This article was published in the following Dove Press journal:

Local and Regional Anesthesia

30 March 2012

Number of times this article has been viewed

\author{
Amit Lehavi \\ Boris Shenderey \\ Yeshayahu (Shai) Katz \\ Department of Anesthesiology, \\ Rambam Health Care Campus, \\ Haifa, Israel
}

Correspondence: Amit Lehavi Department of Anesthesiology, Rambam Health Care Campus, Haaliya St, Haifa, Israel Tel +972502 06I 4I9 Email amit.lehavi@gmail.com
Abstract: We report a case of a patient, chronically treated with oral lithium, who presented with an extremely prolonged (42-hour) duration of sensory and motor paralysis following an uneventful infraclavicular block for hand surgery that was performed under ultrasound guidance using bupivacaine and lidocaine. Due to its direct effect on nerve conduction of action potential, we propose that lithium may have had a role in the unusually prolonged duration of a peripheral nerve block.

Keywords: nerve blockade, lithium, duration, anesthesia

\section{Introduction}

Peripheral nerve blocks are of great importance in anesthesia and may provide painless, safe, and inexpensive anesthesia with long-lasting analgesia. Numerous systemic and local effecting medications, many of which are still in daily clinical use, may alter the onset, analgesic effect, and duration of peripheral nerve blocks. Here, we describe the case of a patient, chronically treated with oral lithium, who had an extremely prolonged (42-hour) duration of sensory and motor paralysis following an uneventful infraclavicular block for hand surgery that was performed under ultrasound guidance using lidocaine and bupivacaine.

\section{Case report}

A 46-year-old woman was scheduled for elective hand surgery. Her medical history was significant for bipolar disorder, chronically treated with oral lithium carbonate $750 \mathrm{mg}$ /day during the 4 years prior to the surgery. Blood lithium levels 2 days prior to the surgery were $0.45 \mathrm{mEq} / \mathrm{L}$ (therapeutic values usually considered are between 0.6 and $1.2 \mathrm{mEq} / \mathrm{L}$ ). She had had no previous surgery, except minor dental procedures under local anesthesia, and no known allergies.

Due to patient preference for regional anesthesia, an infraclavicular block was performed under ultrasound guidance using a $22 \mathrm{G}$ stimulating needle (Polymedic ${ }^{\circledR}$; te me na SAS, Carrieres-sur-Seine, France). Each one of the three cords of the brachial plexus was separately visualized using an in-plane short axis approach and concomitantly electrically stimulated by nerve stimulator, after which a local anesthetic "cuff" was injected individually around each cord, using $10 \mathrm{~mL}$ of plain bupivacaine $0.25 \%$ (Kamada, Beit-Kama, Israel) and lidocaine 1.5\% (Rafa Laboratories Ltd, Jerusalem, Israel) solution $(0.1 \mathrm{mg} / \mathrm{kg}$ and $0.075 \mathrm{mg} / \mathrm{kg}$, respectively, totaling $30 \mathrm{~mL})$. Neither paresthesia nor pain was elicited during the injection. Sensory block was evaluated 
using pinprick and was satisfactory 12 minutes following the injection. No adverse effects were observed.

In the ward, the patient complained of residual intense block, both motor and sensory, which persisted for approximately 20 hours and wore off slowly until it was absent 42 hours following the injection of the local anesthetic solution.

Follow-up at 1 week and 1 month revealed no motor or sensory deficit, no paresthesia, and no sign of nerve damage.

No ethical issues arose from the medical management of this case.

\section{Discussion}

Lithium is an alkali metal with a long history of clinical use for bipolar disorders ${ }^{1}$ and has been utilized as an adjuvant for neuropathic pain ${ }^{2}$ and fibromyalgia. ${ }^{3}$

The conduction of action potentials through nerve fibers is dictated by the intra- and extracellular concentrations of ions, as well as being a result of the adequate function of the ion channels within the cell membrane. Based on the Goldman-Hodgkin-Katz voltage equation, a permanent presence of the lithium ion in the extracellular fluid alters the membrane resting potential ${ }^{4}$ and, hence, might significantly alter the conduction of action potentials.

The period of arrested action potentials induced by local anesthetics is reliant upon the reversibility of the voltagegated sodium channel blockade. Gold and Thut ${ }^{5}$ showed that if the concentration of lithium ions increases, the potency of local anesthetics conduction block increases concomitantly in an in vitro rat model. In this study, the effective dose of lidocaine-induced block on the voltage-gated sodium channel TTX-S INa in the presence of physiologic concentrations of $\mathrm{Na}^{+}(35 \mathrm{mM})$ was lowered by approximately $80 \%$ with the presence of $\mathrm{Li}^{+}$ions. Lilley and Robbins ${ }^{6}$ demonstrated an increased potency of local anesthetics (procaine, lidocaine, and benzocaine) in an isolated frog sciatic nerve with the presence of $\mathrm{Li}^{+}$compared with $\mathrm{Na}^{+}$.

In the present case, the motor and sensory block lasted 42 hours, although the literature and our experience show that using this dose of local anesthetic usually provides an effect that lasts $10-16$ hours $^{7}$ or less. ${ }^{8}$ We suggest that lithium could have elicited the prolonged duration of the peripheral nerve block. This relation may exist, despite subtherapeutic levels of lithium, due to different effects of the ion on the central and peripheral nervous systems.

Since the length of analgesia is of great significance when a single-injection nerve block is applied, further studies are needed to evaluate the effects of lithium on the duration of motor and sensory nerve block in humans.

\section{Disclosure}

The authors report no conflicts of interest in this work.

\section{References}

1. Grandjean EM, Aubry JM. Lithium: updated human knowledge using an evidence-based approach. Part II: Clinical pharmacology and therapeutic monitoring. CNS Drugs. 2009;23(4):331-349.

2. Shimizu T, Shibata M, Wakisaka S, Inoue T, Mashimo T, Yoshiya I. Intrathecal lithium reduces neuropathic pain responses in a rat model of peripheral neuropathy. Pain. 2000;85(1-2):59-64.

3. Tyber MA. Lithium carbonate augmentation therapy in fibromyalgia. CMAJ. 1990;143(9):902-904.

4. Thiruvengadam A. Effect of lithium and sodium valproate ions on resting membrane potentials in neurons: an hypothesis. J Affect Disord. 2001;65(1):95-99.

5. Gold MS, Thut PD. Lithium increases potency of lidocaine-induced block of voltage-gated $\mathrm{Na}^{+}$currents in rat sensory neurons in vitro. J Pharmacol Exp Ther. 2001;299(2):705-711.

6. Lilley SJ, Robbins J. The action of local anaesthetics on the compound action potential is altered by the nature of the permeant ion in frog nerve. Neurosci Lett. 1998;252(1):41-44.

7. Cucchiaro G, Ganesh A. The effects of clonidine on postoperative analgesia after peripheral nerve blockade in children. Anesth Analg. 2007;104(3):532-537.

8. Taboada M, Rodriguez J, Amor M et al. Is ultrasound guidance superior to conventional nerve stimulation for coracoid infraclavicular brachial plexus block? Reg Anesth Pain Med. 2009;34(4):357-360.
Local and Regional Anesthesia

\section{Publish your work in this journal}

Local and Regional Anesthesia is an international, peer-reviewed, open access journal publishing on the development, pharmacology, delivery and targeting and clinical use of local and regional anesthetics and analgesics. The journal welcomes submitted papers covering original research, basic science, clinical studies, reviews \& evaluations,

\section{Dovepress}

guidelines, expert opinion and commentary, case reports and extended reports. The manuscript management system is completely online and includes a very quick and fair peer-review system, which is all easy to use. Visit http://www.dovepress.com/testimonials.php to read real quotes from published authors. 